\title{
Appraisal in the Public Service, Instrument of Human Resource Management
}

\author{
Claude BARREIX \\ Visiting professor, Paris-Est Créteil University \\ AEI Institute, Public governance laboratory: LARGOTEC \\ 61, Avenue du général De gaulle 94010 Créteil \\ France \\ E-mail : claude.barreix@u-pec.fr
}

Accepted: November 23, 2013

doi:10.5296/ jpag.v3i4.4930 URL: http://dx.doi.org/10.5296/ jpag.v3i4.4930

\begin{abstract}
The purpose of this article was to put forward staff appraisal process in the Public Service of advanced countries. Even if British and French Civil Services have different characteristics coming from their specific cultures, even if staff appraisal development has followed different rhythms, they meet together to consider that appraisal is a key instrument to improve public performance and Human Resource Management.

Pay related to performance (PRP) triggers international debates because some consider it as ineffective and a source of discord inside a working team. But the two countries have to address the problem to find how to motivate their staff. The British civil servants seem less reluctant to PRP than their French homologues who feel more comfortable with a collective approach of appraisal, even if this system is criticized because some poor contributors may hide themselves behind good performers. The solution that could be prescribed would consist in using a collective approach of appraisal in combination of a system rewarding individual performers, in order to motivate staff individually and collectively as well.
\end{abstract}

Keywords: Public Service; Human resource; appraisal; public performance; motivation; pay 


\section{Introduction}

Appraisal has become for a long time a key element of a successful human resource management in the Public Service. As most management methods, modern staff evaluation whose ambition is to measure performance and try to reward it, was born in the private sector and exported to the Civil Service in OECD countries in particular.

Even if there was a tradition in the different public services to evaluate civil servants mostly on behaviour criteria, such modern methods did not appear before the 1980s.

The context of appraisal in the public services of advanced countries is that of a growing need to control public expenditures and ensure efficient use of public resources. These processes have gradually become a major element to implement a good human resource management aiming to discriminate staff from objective results, to listen to managers as well as employees' expectations, to promote professional development, to improve services running and to motivate staff too.

So the British and French Civil Service following different rhythms have reformed their staff evaluation systems. Until the 1970s a classical top down reporting by the manager, was used by the British service but from 1979, with the 'New Public Management' staff appraisal has been introduced and this approach was consecrated in 1988 from the 'Next Steps'coming from Ibbs' report1 Great Britain even became one of the first countries to introduce a link between assessment of performance and pay.

France started later to renovate its civil servants evaluation dating from 1946 founded on marking. As soon as 1989 with the 'circulaire Rocard' 2 and the 'Le renouveau du service public' (public service renewal) the idea emerged to overcome the ancient top down process 'système de notation' and long and various experiments took place in many ministries, universities and other bodies. But concrete measures generalising a modern approach of appraisal did not appear before 2004 and linked-to-pay appraisal today remains limited to executives and managers. This process was consecrated in 2012 when the marking system was abandoned.

So it seems relevant through the examples of these two countries, with their specific culture and vision of the Civil Service, to consider how appraisal is now implemented, what is measured in these processes and what the consequences on staff situation are, from a financial point of view.

\section{However, what does appraisal consist of in the Public service?}

Modern appraisal in advanced countries is a process in which a manager appreciates behaviour at work and results of his (her) subordinates. In his (her) turn this manager, subordinate to higher-ranked managers, will be evaluated by his (her) superior too.

The process is monitored by the HR manager and generally starts at the beginning of the year by an interview between the manager and the employee. This appointment takes place in a

\footnotetext{
${ }^{1}$ Sir John Ibbs was a Margaret Thatcher's advisor

${ }^{2}$ Michel Rocard had been the French Prime Minister from 1988 to 1991
} 
closed room, without telephone and any visitor, for an average duration of one hour. This interview does not deal with any daily current business but concentrates on the subordinate's activities during a given period, generally the last year

The aims of the interview are:

- to appreciate the reaching of the targets defined at the beginning of the previous year;

- to register acquired competences;

- to set targets ( 4 to 6 are easier to follow than a lot of them) for the present year, measured by indicators respecting the SMART3 system;

- to discuss about possible organization improvements in the service;

- to examine professional developments needed by the subordinate and prescribe necessary training;

- to examine career perspectives;

- to express (if relevant) proposals about promotions or/and granting linked to performance financial bonus.

A few days after the interview both appraiser and subordinate sign a document written by the appraiser, reporting the contents of the interview. This document generally contains a section in which the subordinate can write some observations concerning the appraiser's appreciations. If the subordinate is not satisfied with his (her) appraisal, he (she) may submit a complaint first to the appraiser, then to the managerial staff and even to a specialized committee. The appreciations are thus not irreversible.

In order to complete this appraisal procedure, certain ministers or public bodies, often inspired by various practices in the private sector use $360^{\circ}$ evaluation for managers. By measuring their managerial practice through the opinion of their superiors, their subordinates, colleagues and even their external partners, the upper managers try to permit the managers to be conscious of their weaknesses and to improve their managerial methods, sometimes with the help of a coach. However these practices are mostly limited experiments.

\section{How is the system implemented in the two countries?}

The British system is a comprehensive one: it is decentralised except for the senior Civil Service. So every administrative unit can develop its own appraisal system. This system is internationally recognized because it has been submitted to several audits in order to improve its running (e.g.: Sir Michael Bichard's report in 19994; Makinson's report5 in 2004...)

The example which is often given is that of the Cabinet Office, because it is considered as one of the most comprehensive, objective and performing systems of appraisal. The process starts with a collective approach: a target agreement between employers and employees,

\footnotetext{
${ }^{3}$ Indicators have to respect the SMART characteristics: Specific, Measurable, Time-Bound

${ }^{4}$ Lord Michael Bichard was a chief executive in both central and local governments in the UK

5 John Mackinson, chairman of International publishing company Penguin Random House
} 
taking place in April is set according to the 'SMART system', and competences required to reach these targets are defined. The superior discusses the targets which have to be particularly followed with the employees. Every three months, there are review meetings in order to appreciate the present situation versus the targets agreement.

A certain importance is granted to the mid-year review.

In the period from December to March (the following year) there is an individual appraisal of the level of reaching of these targets and also an assessment of employee's competencies concerning particularly communication, target attainment, leadership, ability to solve problems, cooperation and partnership at work.... The appraiser's conclusions appear in the 'pay form'. When performance is considered insufficient a 'poor performer's policy' is automatically triggered in order to improve his (her) future performance.

In parallel, the employee produces a self-assessment; a pay committee will take the final decision on the appraisal with some consequences on his (her) salary when a financial bonus is granted.

The French system is more recent because the Government knew difficulties to get rid of the ancient procedure, founded on a rating system which was very remote from the notion of target. Until 2004, even if many experiments helped to overcome the ancient top down system, oppositions from the unions and scepticism from certain managers were an important break to the development of a modern, less subjective appraisal procedure. However the French culture of centralization implied the development of a common legal frame for public staff evaluation,

Generally there is not a collective reflection about the targets of each unit but the managers define them taking account of the general objectives set for their direction At the beginning of the year, each employee gets an appointment with his (her) superior and targets are then assigned to him (her) after a discussion. The latter starts with a review of the targets set for the previous year and the level of their reaching by the employee is then checked. Weak results are analysed: employee may have failed due to a lack of training or self-investment, targets may have also been too ambitious, or work conditions may have been unfavourable... The exchanges also deal with the competences manifested and those that need to be developed, particularly to get a promotion. In the French Civil Service according to the 'career system' the employees are generally obliged to pass a competition examination in order to reach the upper grade, that can be however prepared through internal permanent training. But the possibilities to mobility for a new post may be examined and questions about work organization in the service may be also evoked.

The interview report may contain for certain staff, essentially executives or managers, a proposal about a certain amount of financial bonus.

This annual appointment is the only one to be mandatory but other less formal interviews take place more and more often in order to operate intermediate checking.

In both countries, the human resource manager publishes specific guidelines in order to help 
appraisers to manage evaluation procedures. Training actions are organized for appraisers and sometimes for the staff who will be appraised.

\section{What are the consequences of appraisal in the two countries' systems?}

Appraisal is useful for both managers and employees: its aim is to improve quality of the Public service that is indeed a great motivation for most civil servants The interview must permit improvements in the service: increasing competencies and skills through training actions, increasing productivity through better organization. However numerous criticisms are expressed by employees and managers about appraisal procedure, particularly concerning the way it is led. So it seems that certain appraisers focus on the targets and completely forget the professional development of their subordinates.

These situations are reported in different studies on the subject as in the Makinson's Report in 2004 which expresses recommendations particularly concerning the definition of incentives.

Mandatory training on appraisal seems a good solution to these problems, for managers as soon as they become line managers and lead a team.

But appraisal clearly appears as a major opportunity to set forth incentives by means of better remuneration and/or of better career perspectives.

In Britain 'Performance-Related Pay' (PRP) is historically more accepted amongst the civil servants. When the National Audit Office shows that promotions have become very difficult for many years, except for top managers, the British civil servants seem more interested in direct financial incentives. Moreover the British people are accustomed to the culture of performance and individual success is usually encouraged by British society.

It is to be reminded that each appraiser formulates a pay recommendation in the form of bonus proposals. But the final decision is taken by a pay committee composed of senior managers of the administrative unit to which the subordinate belongs. There is a pay scale in order to avoid going beyond the limits of the budget allocated to the unit.

But this system is often contested because of the quota system which may introduce a feeling of injustice amongst the staff. There are three predetermined tranches: top, middle and bottom in which staff are dispatched according to the targets being reached or even surpassed, reached but not surpassed, or not reached at all.

Sometimes the results appear contestable for instance when some targets founding appraisal are difficult to measure so thence the system may appear unfair.

Some surveys have indeed highlighted the limits of PRP considering that even if there are fixed ceilings in bonus determination, the system appears costly for the administrations meanwhile the individual allocations do not often seem important (8\% of the total remuneration according to the conclusion of a 2008 survey) to represent a real incentive for the staff. 
In France PRP is traditionally ill accepted, mostly by the unions who consider that the finality of the public action is different from the commercial one and that it is not relevant to discriminate employees and even managers through target reaching. According to them the Public Service interest would be the major incentive which could motivate managers and employees as well.

The only concession given to the system is to consider appraisal as an element of appreciation to permit a quicker promotion, but it comes behind two main elements: age and seniority. It has to be considered that for public employees, seniority is the masterpiece of pay increases. Accessory remunerations are not generally discriminated and when they are that represents a tiny part of their salary. In France another factor plays a large part in PRP reluctance; the egalitarian system which is an important founding of the French society and civil servants very often put forth this principle to oppose appraisal.

However, the French system of public resource management has slowly led the way to PRP from the 2000s but only concerning executives and managers.

Directors and senior managers are now accustomed to get an important part of their wage by annual bonuses reaching sometimes until $20 \%$ of their total remuneration.

The 'prime de fonctions et de résultats' (PFR) experimented in 2008 is now diffused in the Civil Service. It is composed of a part linked to the level of functions occupied, appreciated on the basis of a post quotation, and a part related to results comprising a bonus determined through the appraisal procedure. However this bonus does not often represent more than $6 \%$ of their total remuneration. This rate might be even more reduced in a few months as a reform of the PFR system is pending.

Reviews led by official bodies as OECD from the 2000s show that a minority of executives and managers, even in Great Britain, consider that there is a good correlation between performance improvement and financial bonuses. But the question is to know, as it was noted previously for both British and French Civil Service, if the part allotted to financial bonus is important enough to be a real incentive.

OECD reports insist in particular on the danger of pay discriminations in the context of promotion of team works which now prevails in modern administrations. How to conciliate indeed good team management with permanent competition inside the team between the different co-workers?

Certain administrations in Great Britain and France as well, have experimented collective financial bonuses. Though this system seems to be used now in certain British companies as the Economist reported it in one of its July issues, it is suspected to lead to injustice because 'poor contributors' are not discouraged to hide themselves behind good performance of the team. In France a collective appraisal procedure has been introduced in the Public service since 2011 after an experiment led in the Ministry of economy and finance. Named 'prime d'intéressement collectif', its aim is to reward a team which has reached some objective, generally with a maximum of five, defined by the Direction. The reward varies according to the number of targets met. 


\section{MInstitute Macrothink $^{\text {Int }}$}

The unions are less reserved about this procedure because there is no discrimination between all the employees and managers who receive the same amount of bonus whatsoever their grade and because it does not introduce competition between them.

However certain criticisms may be expressed towards this procedure. Due to budget restriction, the actual amount of money given is not significant: about $1 \%$ maximum of the total wages for the less paid employees, that is to say a valueless sum for a manager. So it seems difficult to consider it as an incentive.

Even if a provision in the decree says that a very poor contributor might be excluded from this benefit, certain employee weakly invested in the team work may receive equal bonus than others who contribute a lot and the latter may be discouraged: if certain civil servants and their representative think that this system could replace the PRP system, it would then be difficult to reward and so to motivate those who accomplish the biggest efforts in the Public Service.

\section{Conclusion}

As a conclusion, appraisal appears nowadays as an unavoidable instrument of a modern human resource management in the Public service and going back is not considered by the administrative authorities, even in France where hesitation on the principle is more important than in Great Britain. The system has indeed proved that appreciations founded on targets -whatever their perfectibility- was better than the previous ones, because it presents more objectivity. The collective procedure leading to an agreement on targets used by the Cabinet Office could deserve to be experimented in the French Civil Service.

Moreover definition of targets for the staff inside a unit, permits to work from common basis and gives coherence to the work of the team. Frequent conducts of audits and surveys are relevant instruments permitting to bring improvements to the system itself and to its acceptability by the staff, particularly when it contains Pay-Related Performance. A combination of individual and collective appraisal, with separate bonuses as it begins to be used for the French civil servants seems to be a good compromise because both team and personal may so be rewarded at the height of their investment. But the problem that remains to be solved is that of the cost of these bonuses if the public organizations wish they be real incentives.

\section{References}

Dr Christoph Denmke (June 2007) 'Performance assessment in the Public Services of the EU member states' European Institute of Public Administration Maastricht

Available: www.bmi.bund.de

Elsa Pilichowki OECD (March 2009) in Perspectives Gestions Publiques $\mathrm{n}^{\circ} 30$ 'La rémunération à la performance est-elle efficace ?'

Available: www.insitut.minefi.gouv.fr 
Luis Carlos Perreira (2004) 'Democracy and the NPM'

Available: www.oxfordscharship.com

London School of Economics and Political science (2011) vol 51 issue 5 'Next steps: Ministerial responsibility and government by agency'

Available: onelinelibrary.villey.com

Circulaire du 22 février 1989

Available: www.dsi.cnrs.fr

'Prime de fonctions et de résultats' (220décembre 20008) décret 2008-1533

Available: www.legifrance.gouv.fr

'Prime d'intéressement collectif' circulaire du 29 août 2011

Available: www.legifrance.gouv.fr 